"The municipal councils in the crisis

\title{
As câmaras municipais \\ na crise da Independência: \\ Minas Gerais, Mato Grosso e Goiás \\ (1821-1825)
}

of Brazilian Independence: the

provinces of Minas Gerais, Mato

Grosso and Goiás (1821-1825)"

\section{André Nicacio Lima}

Bolsista PET/SESU de Inciação Científica (Departamento de História, FFLCH-USP), sob orientação do Prof. Dr. István Jancsó.

\begin{abstract}
Resumo
A pesquisa aqui apresentada é parte de um projeto coletivo de iniciação cientifica que tem por tema central o papel desempenhado pelas câmaras municipais no processo de Independência do Brasil. As câmaras de diversas províncias são entendidas como importantes bases institucionais da dinâmica politica, de que resultam a constitucionalização da monarquia portuguesa, a Independência e a fundação do Império do Brasil. Este informe expõe as questões centrais, os caminhos percorridos e os objetivos do projeto, bem como os da pesquisa individual referente, especificamente, às câmaras das vilas e cidades das províncias de Minas Gerais, Goiás e Mato Grosso.
\end{abstract}

\begin{abstract}
The project hereby introduced is part of an undergraduate group research project whose central subject is the role played by the municipal councils during the process of Brazilian Independence. The councils of various provinces are understood as important institutional foundations in the political dynamics which resulted in the shift of the Portuguese Monarchy into a constitutional form of government, the Independence of Brazil and the formation of the Brazilian Empire. This report aims to present the chief purposes, problems and stages of this group research as well as the individual project dealing specifically the local councils of Minas Gerais, Goiás e Mato Grosso.
\end{abstract}


Os demais integrantes e seus respectivos recortes são: Bruno Fabris Estefanes (Grão Pará), Fernanda da Silva Ramos (São Paulo), Mainá Pereira Prada Rodrigues (Rio Grande de São Pedro) e Maria Inês Panzoldo de Carvalho (Rio de Janeiro e Espírito Santo). Participaram também do grupo Julia Relva Basso e Andréa Paula Placitte.

2

0 projeto, financiado pela FAPESP, foi iniciado no primeiro semestre de 2004 e conta com os sub-projetos "Nação e Identidades" e "Estado e Soberania", no qual se inclui esta pesquisa.

3

Para um panorama geral da "adesão do Brasil ao apelo constitucional", em que estão presentes as Câmaras em diversos momentos, ver Márcia Regina Berbel. A Nação como Artefato - Deputados do Brasil nas Cortes Portuguesas - 1821 1822. São Paulo: Hucitec, 1999, especialmente o capitulo 2. Para outro panorama geral, o da "adesão das Câmaras à figura do Imperador", conferir lara Lis Carvalho Souza Revista Brasileira de História. São Paulo, no 36, vol.18, 1998. Sobre a publicação e o juramento, pelas Câmaras, da constituição de 1824, João Armitage. História do Brasil. São Paulo: EDUSP; Belo Horizonte: Itatiaia, 1981.p. 87. Também há diversas referências em obras gerais sobre o processo de Independência, como a de José Honório Rodrigues. Independência: Revolução e Contra-Revolução. Vol. 1: A evolução politica. Rio de Janeiro: Francisco Alves, 1975. Porém, como a diversidade é uma característica fundamental do próprio processo, algumas das situações citadas são específicas a certas províncias. Sobre as dinâmicas políticas provinciais, a segunda parte - "Das Independências" - Carlos Guilherme Mota. 1822: Dimensões. São Paulo: Perspectiva, 1972; as comunicações das mesas dedicadas à "Independência nas partes do Brasil" no Seminário Internacional Independência do Brasil: História e Historiografia, realizado em 2003 e ainda não publicado; e o volume "Dispersão e Unidade", Sérgio Buarque de Holanda. História Geral da Civilização Brasileira. tomo II - 0 Brasil Monárquico, vol.2. São Paulo: Difel, 1962.

4

Por exemplo, para Caio Prado Jr é a "forma popular com que se constituem e funcionam [...] a origem da força com que contarão mais tarde as Câmaras para agir efetivamente, como de fato agiram, e intervir muitas vezes decisivamente, nos sucessos da constitucionalização, independência e fundação do Império. Será o único órgão da administração que na derrocada geral das instituições coloniais, sobreviverá com todo seu poder, quiçá até engrandecido." Caio Prado Jr. Formação do Brasil Contemporâneo (Colônia). 14a edição, São Paulo: Brasiliense, 1972, p. 319. Recentemente, lara Lis Carvalho Souza. op. cit. e Denis Bernardes trataram do problema, este último em sua comunicação no Seminário Internacional Independência do Brasil: História e Historiografia, realizado em 2003 e ainda não publicado.
A pesquisa coletiva, na qual este trabalho se insere, tem por objeto a atuação das câmaras municipais de diversas províncias, como uma das bases institucionais da dinâmica política que, a partir de 1820, com a Revolução do Porto, iria desdobrar-se em todo o Reino do Brasil. 0 grupo, formado no início de 2004, conta hoje com cinco bolsistas de iniciação científica, cada um responsável pela investigação das câmaras de uma ou mais províncias ${ }^{1}$. Nesta pesquisa individual, são estudadas as 21 vilas e cidades então existentes em Minas Gerais, Goiás e Mato Grosso. 0 trabalho está inserido ainda no Projeto Temático "A fundação do Estado e da nação brasileiros (c.1780c. 1850) $)^{\prime \prime}$.

Com aproximadamente um ano de atividades, do total previsto de dois anos e meio, o desenvolvimento da pesquisa pode ser dividido em três fases, ainda que imbricadas. Inicialmente, foram estabelecidos, além do tema, os problemas centrais, as referências teórico-metodológicas, os objetivos e o plano de trabalho. A preparação de projetos individuais, a partir da pesquisa bibliográfica geral e especifica e a discussão de todo o grupo em torno de cada um desses projetos constituiram as principais atividades nesta primeira fase. Em seguida, os integrantes do grupo passaram a trabalhar, também por meio de pesquisa bibliográfica, seus respectivos recortes espaciais. 0 objetivo desta fase era o de aprofundar o conhecimento das províncias estudadas, não apenas na esfera política, para que, então, fossem construídos instrumentos de pesquisa (cronologias, mapas, tabelas demográficas, listagens da documentação e da bibliografia existentes) que poderiam ser utilizados a seguir. Por fim, a pesquisa documental e a análise bibliográfica especifica permitirão a redação final do trabalho, a principal atividade do próximo ano.

0 recorte espacial adotado para o projeto coletivo é o Reino do Brasil, sendo que a divisão do trabalho inclui nove províncias. As balizas cronológicas são específicas para cada região, podendo variar conforme a duração da crise política em cada situação concreta. 0 recorte desta pesquisa individual têm início com os primeiros desdobramentos da Revolução do Porto (juramentos à Constituição por fazer, destituição de governadores, formação de Juntas, eleições para deputados) e término com a relativa estabilidade das províncias em questão (e com o fim da dualidade administrativa em Goiás e Mato Grosso), o juramento da Constituição de 1824 e a posse dos primeiros presidentes de província, em 1824 (Minas Gerais e Goiás) e 1825 (Mato Grosso).

\section{A delimitação do objeto, da bibliografia e da documentação}

As câmaras municipais tiveram uma atuação intensa nos processos que marcaram, de diferentes formas, os desdobramentos da Revolução do Porto, em cada província do Reino do Brasil: prestaram adesão à Constituição da Nação Portuguesa que fariam as Cortes; tomaram parte nos conflitos politicos (denúncia e destituição de governadores, confrontos com as juntas governativas); participaram da eleição dos deputados para as Cortes e dos membros das juntas de governo, assim como de sua própria instalação; comunicaram-se com o Principe Regente, ora manifestando apoio e adesão, ora discordando deste; prestaram, também, pessoalmente homenagens ao soberano na Corte ou em suas "viagens de adesão"; publicaram e juraram - ou, em alguns casos, pelo contrário, se opuseram - à Constituição outorgada pelo Imperador em 1824. ${ }^{3}$

A importância da atuação política das câmaras municipais nessa crise política é, geralmente, explicada tanto por serem essas instituições tradicionais da prática política, com uma importante experiência de negociações e conflitos com os poderes metropolitanos, quanto por representarem setores sociais mais amplos, se comparadas a demais instituições da época ${ }^{4}$. 
Em especial nas últimas duas décadas, a história político-administrativa da colonização deixou de ser tarefa quase exclusiva de brasilianistas como Charles Boxer, Russel-Wood e Stuart B. Schwartz. Para as câmaras municipais coloniais, Maria Fernanda Baptista Bicalho. "As Câmaras ultramarinas e o governo do Império". In: João Fragoso; Maria Fernanda Baptista Bicalho; Maria de Fátima Silva Gouvêa (orgs.). O Antigo Regime nos Trópicos: a dinâmica imperial portuguesa (séculos XVI-XVIII). Rio de Janeiro: Civilização Brasileira, 2001. Charles Boxer. "Conselhos municipais e irmãos de caridade" in 0 império marítimo português. São Paulo: Companhia das Letras, 2002. John Russell Wood. "0 Governo Local na América Portuguesa: um estudo de divergência cultural". Revista de História. São Paulo, vol. LV, ano XXVIII, 1977, p. 25-79.

6

As Câmaras Municipais e a Independência. 2 vols. Rio de Janeiro: Conselho Federal de Cultura, Arquivo Nacional, 1973

7

Para as Câmaras de Minas Gerais, "Memórias Municipais". Revista do Arquivo Público Mineiro. 1896, vol. 1, 1a parte. Citado por Ana Rosa Cloclet da Silva. "Identidades em Construção. 0 processo de politização de identidades coletivas em Minas Gerais, de 1792 a 1831." Relatório I do projeto de pós-doutorado. Abril de 2004. Esta documentação ainda não foi consultada para a pesquisa.

Ao que parece, a única vila destas províncias que não conta com documentos publicados é Jacuí, em Minas Gerais. A dúvida quanto a outras lacunas se deve à dificuldade em saber, até o momento, se houve mais de uma câmara "interina" funcionando simultaneamente no Norte de Goiás.

0 corpus documental relativo a Mato Grosso pôde ser ampliado com as pesquisas realizadas em julho de 2004 no Arquivo Publico de Mato Grosso (APMT). Com o material emprestado pelo Projeto Temático, foram feitas cerca de 600 digitalizações, incluindo, além da documentação manuscrita e impressa, algumas publicações do Instituto Histórico e Geográfico de Mato Grosso (IHGMT).
Compreender questões como essas torna-se relevante não apenas para a história política da Independência - e, nesse sentido, parte importante do conhecimento sobre a formação do Estado e da nação brasileiros-, mas também para a história das câmaras como instituições político-administrativas. Estudos semelhantes têm enriquecido o conhecimento sobre aspectos políticos e institucionais da colonização, pouco pesquisados anteriormente ${ }^{5}$. Contudo, o periodo crítico de que resulta a Independência não foi ainda abordado por esta historiografia.

A possibilidade de esta pesquisa contribuir para o estudo das câmaras como instituições político-administrativas não significa, entretanto, que este seja o foco do trabalho. Essas instituições estão sendo investigadas na medida em que se envolvem na dinâmica politica de que resultam a constitucionalização da monarquia portuguesa, a Independência política do Brasil e a fundação do Império. Ou seja, é em sua atuação política - que abrange apenas uma parte das atribuições das câmaras - que se situam os problemas, as trajetórias e as hipóteses de pesquisa que serão apresentados neste informe, e a esfera administrativa (econômica, jurídica, fiscal) apenas tem importância desde que ajude a explicá-la.

Se a atuação política das câmaras é o objeto da pesquisa, os problemas centrais se referem, mais especificamente, a uma série de relações cujas bases institucionais fundamentais foram câmaras municipais de diversas partes do Reino do Brasil. Tais relações são aquelas que se materializaram em inúmeras representações remetidas à Corte entre os anos de 1822 e 1823 e que, embora muito diversas entre si, tinham em comum declarações de adesão à Independência política em relação a Portugal e à Aclamação de D. Pedro como Imperador do Brasil. A escolha por centrar a pesquisa nestas relações é justificada por sua importância para a compreensão do processo de Independência, da construção do projeto político do Império e da natureza do poder no Primeiro Reinado.

As comunicações de adesão foram, em parte, publicadas em uma edição conjunta do Conselho Federal de Cultura e do Arquivo Nacional6. No caso das províncias de Goiás e Mato Grosso ${ }^{7}$, não foram encontradas outras publicações específicas. Existem lacunas relevantes, inclusive em relação a províncias inteiras, na publicação do Arquivo Nacional. E mesmo nos casos em que foram incluídos documentos de todas, ou quase todas, as vilas - situação de Minas Gerais, Goiás e Mato Grosso ${ }^{8}$-, a consulta aos arquivos revelou ser esta somente uma pequena parte do material que documenta a atuação das Câmaras na dinâmica política de que resulta a Independência9. Assim, outras fontes primárias - publicadas ou não - devem ser consultadas posteriormente, do que deve resultar uma maior compreensão do processo , mas também do significado destas lacunas.

A pesquisa está centrada, portanto, em um conjunto de relações, com um corpus documental já delimitado e problemas específicos que orientarão sua análise. Para apresentar as principais questões, os caminhos para sua compreensão e as hipóteses trabalhadas, dois conjuntos de problemas serão agora relacionados. 0 primeiro se refere à busca, por setores políticos da Corte, de uma articulação com as câmaras municipais. 0 segundo, às próprias adesões: quantas e quais foram as câmaras que aderiram e por quê, em cada caso concreto, o fizeram ou deixaram de fazer. Um terceiro conjunto de problemas, que se refere à importância política das adesões como um todo, deve ainda ser formulado futuramente para que se possa indicar outros caminhos para a pesquisa.

\section{Problemas e trajetórias de pesquisa}

As manifestações das câmaras junto ao poder central, por ocasião de acontecimentos que consideravam importantes, eram parte da cultura política 
10

"Officio da Camara do Rio de Janeiro á Camara da Villa de Taubaté communicando a resolução de fazer acclamar D. Pedro Imperador do Brasil". Rio de Janeiro, em Vereação extraordinária de 17 de setembro de 1822. In: Documentos para a História da Independência, vol. I, pp. 400401. 0 documento foi encontrado na Biblioteca Nacional do Rio de Janeiro por Maria Inês Panzoldo de Carvalho, a quem agradeço pela indicação e fornecimento de sua transcrição.

11

José Honório Rodrigues. op. cit. p. 261.

12

Idem. pp. 263-264. Em 17 de janeiro de 1823, a Câmara de Mariana informa a José Bonifácio a reunião realizada no mesmo dia "a fim de retratar-se a exótica Cláusula inserta na Ata da Aclamação de Sua Majestade o Imperador". A reunião foi marcada após o recebimento do Ofício em que Bonifácio exige a "retratação da cláusula inserta no Auto de Aclamação de Sua Majestade Imperial, que pretendia do Mesmo Senhor o prévio juramento de guardar uma Constituição". As Câmaras Municipais e a Independência. op. cit. Volume 2. docs 235 e 236. pp. 167-168.

13

Segundo José Honório Rodrigues, "só as províncias do Rio de Janeiro e de São Paulo retrataram a cláusula do juramento prévio". op. cit. p. 280.

14

Por exemplo, na Ata de vereação de 7 de outubro de 1822, na Vila de São Bento de Tamanduá em Minas Gerais: "acordaram [o Juiz presidentes, os ex-vereadores e o ex-procurador] em abrir um ofício acompanhado de Instruções que mandaram registrar, vindas do Senado da Câmara do Rio de Janeiro, e como seu objeto seja a ratificação do povo desta Vila para a aclamação do Senhor Dom Pedro de Alcântara, Primeiro Imperador Constitucional do Brasil, jurando previamente a mesma Constituição [...] foram todos de unânime sentimento que desde já se principiasse a manifestar o júbilo e prazer do Povo desta Vila [...]".As Câmaras Municipais e a Independência. op. cit. Volume 2. doc. 208a. p. 131. que orientava suas práticas. Assim como se manifestaram quando informadas da Aclamação de D. Pedro como Imperador, diversas municipalidades o fizeram em outros momentos importantes, como a chegada da família real, em 1808; a elevação do Brasil a Reino Unido de Portugal e Algarves, em 1815; a coroação de D. João VI, em 1816; a partida do monarca, em 1821; e o "Fico" de D. Pedro, em janeiro de 1822. Porém, as manifestações de adesão à Independência e ao projeto imperial parecem ter sido também respostas à busca de articulação por parte de grupos políticos na Corte.

Para José Honório Rodrigues, a articulação das adesões e a forma como seriam expressas teriam sido objeto de disputa entre projetos distintos. Por um lado, o Senado da Câmara do Rio de Janeiro inclui, em uma circular enviada a diversas outras câmaras, a condição de o Imperador prestar "previamente um juramento solene de jurar, guardar, manter, e defender a Constituição, que fizer a Assembléia Geral, Constituinte e Legislativa Brazílica"10, o que seria uma garantia de respeito à Constituição após a ruptura com as Cortes. Por outro, para o projeto de José Bonifácio, a aclamação das Câmaras, sem representação nacional, seria uma "forma hábil de conciliar a exigência liberal da aclamação e os direitos dinásticos"11. Para este, portanto, "era preciso anular a cláusula que já começara a aparecer nas atas das outras Câmaras provinciais", o que consegue, a 10 de outubro de 1822, dois dias antes da Aclamação ${ }^{12}$.

Não sabemos, no atual estágio da pesquisa, quais câmaras receberam a circular, nem em que proporção foram incluídas em suas manifestações a condição do juramento prévio ${ }^{13}$. Quanto às vilas de Goiás e Mato Grosso não há referências na documentação publicada que atestem o recebimento. 0 que sabemos é que o documento remetido a Taubaté não foi o único a incluí-la, e que houve casos, em vilas de Minas Gerais, em que se fez a Aclamação na forma proposta pelo documento ${ }^{14}$. Como se nota, há mais dúvidas do que certezas quanto a estas relações entre a Câmara do Rio de Janeiro, as demais câmaras do Reino e o ministro José Bonifácio. 0 certo é que não é possivel uma boa compreensão das adesões sem o mapeamento destas relações.

0 segundo conjunto de problemas a ser trabalhado exige também um sólido conhecimento sobre cada município das províncias estudadas. Isso porque não basta saber em que proporção as câmaras municipais aderiram ao projeto imperial, mas também os interesses e aspirações que expressava, em cada caso concreto, a decisão de aderir ou não a este projeto e as demandas apresentadas - explícita ou implicitamente - no momento da adesão.

As manifestações das câmaras não representam apenas respostas a projetos políticos articulados na Corte ou, ainda, a reiteração de uma prática política tradicional. Elas representam também os interesses e as aspirações de setores sociais especificos de municipalidades localizadas em regiões muito diferentes entre si. Diferentes na escala humana que representavam; na posição em relação a um sistema de centros e periferias; na inserção econômica e nas tramas de interesses dai estabelecidas; nas formações societárias resultantes de processos de colonização desiguais, apesar da condição colonial comum; na experiência política acumulada pelos grupos que agora se faziam representar pelas Câmaras. A diversidade presente em todas essas variáveis torna seu domínio imprescindivel para a boa compreensão dos problemas colocados. Desconsiderá-la seria conferir autonomia à esfera política, o que resultaria em uma explicação simples e linear, mas que teria por objeto outra coisa que não a realidade.

Além das múltiplas formações societárias existentes no Reino do Brasil, os grupos que se faziam representar nas câmaras estavam inseridos 
15

Sobre a atuação política de diferentes elites em Pernambuco, mas também importante para pensar outras regiões, Evaldo Cabral de Mello. "0 descompasso" in: Evaldo Cabral de Mello. A Ferida de Narciso: ensaio de história regional. Coordenador Lourenço Dantas Mota. São Paulo: SENAC, 2001. pp. 69-90.

16

As Câmaras Municipais e a Independência. op. cit. Volume 2. doc 248. p. 212.

17

Maria Fernanda Baptista Bicalho. op. cit. Também Roberta Giannubilo Stumpf. Filhos das Minas, americanos e portugueses: Identidades coletivas na Capitania das Minas Gerais (1763 - 1792).

Dissertação de mestrado. São Paulo, Universidade de São Paulo, Faculdade de Filosofia, Letras e Ciências Humanas, 2001.

18

A respeito da relação entre conflitos e identidades coloniais, Luciano de A Figueiredo. "0 Império em Apuros: notas para o estudo das alterações ultramarinas e das práticas políticas no império colonial português, séculos XVII e XVIII". In: Júnia F. Furtado (org.). Diálogos Oceânicos. Minas Gerais e as novas abordagens para uma História do Império Ultramarino Português. Belo Horizonte: Editoda da UFMG, 2001, pp. 197254. Sobre as identidades políticas no periodo da Independência, István Jancsó \& João Paulo G. Pimenta. "Peças de um mosaico ou apontamentos para o estudo da emergência da identidade nacional brasileira". In: Carlos Guilherme Mota (org.). Viagem Incompleta: a experiência brasileira (1500-2000). Formação: Histórias. São Paulo: SENAC, 2000.

19

Sobre as estruturas de poder na América Portuguesa, Graça Salgado (coord.). Fiscais e meirinhos. Rio de Janeiro: Nova Fronteira, 1985. Para as mudanças no ordenamento político-institucional depois de 1808, Maria de Fátima Silva Gouvêa. As bases institucionais da construção da unidade. Administração e governabilidade no período joanino (1808-1821). Texto apresentado no Seminário Internacional Independência do Brasil: História e Historiografia. 2003.

Uma interpretação do processo de colonização na perspectiva de um sistema de centros e periferias está em A. J. Russel-wood. "Centros e periferias no mundo Luso-Brasileiro, 1500-1808". Revista Brasileira de História, vol. 18, n 36, 1998.

20

Enquanto participavam de uma dinâmica politica que atingia todo o Reino, duas cidades, uma vila recém-criada e um distrito chegaram a disputar ao mesmo tempo a condição de capital da Província. Romyr Conde Garcia. Mato Grosso (1800-1840): Crise e Estagnação do Projeto Colonial. Tese de doutorado. São Paulo, Universidade de São Paulo, Faculdade de Filosofia, Letras e Ciências Humanas, 2003.

21

A Comarca de São João das Duas Barras, no Norte de Goiás manteve-se separada do governo da capital, Vila Boa, entre setembro de 1821 e abril de 1823. Os partidários do desmembramento tentaram legitimá-lo, primeiro junto às Cortes através de seu deputado eleito e depois nessas formações de maneira diversa. Se essas instituições não representam os interesses e as aspirações de todos os habitantes do município, esse não é um problema que se pode resolver apenas com o uso de expressões como "elites", ou "elites políticas" - termos que tendem a encobrir a enorme diversidade social entre as regiões do Reino ou mesmo dentro de cada região ${ }^{15}$. Além disso, durante esta crise política, o espaço da câmara foi, por vezes, ampliado, como em Vila Rica, onde a 10 de julho de 1822, quando foram reunidas 250 pessoas para discutir e assinar uma representação ao Principe Regente. A reunião teve de ser remarcada, pois já era tarde e ainda havia muitas divergências ${ }^{16}$. Esse episódio evidencia não só a abertura do espaço político da câmara, como também o fato de que a forma e o conteúdo das adesões, por vezes, resultavam de debates bastante intensos.

As câmaras municipais foram os principais espaços da prática política local no período colonial. Elas eram as bases institucionais de negociação com a metrópole17, - mas exerciam também um papel primordial nas negociações e nos conflitos locais. Essas práticas permitiram o acúmulo de experiência política, de formas distintas, nas vilas e cidades de diversas regiões da América Portuguesa. Assim, faz-se relevante conhecer o histórico político dessas vilas e cidades, tanto porque esta experiência orienta as práticas dos homens, quanto porque a partir delas formaram-se identidades coloniais que, quando politizadas em meio à crise, tornam-se uma variável fundamental para entender o sentido da ação política ${ }^{18}$.

Igualmente importante é conhecer a inserção das províncias e de cada uma de suas vilas nas estruturas de poder do Império português e as mudanças em meio à crise estudada. Os domínios dos Bragança eram constituidos por espaços organizados, hierarquicamente, em um sistema de centros e periferias, construído e reordenado durante a colonização e subvertido radicalmente em $1808^{19}$. Ao mesmo tempo, outras relações, de natureza econômica, formaram tramas de interesses que nem sempre seguiam os mesmos sentidos que os das rotas administrativas.

Além da diversidade resultante do processo de colonização portuguesa na América, cada uma dessas regiões vivia dinâmicas políticas próprias, ainda que estivessem relacionadas entre si e articuladas pelos centros dinâmicos de Lisboa e do Rio de Janeiro. Problemas que não eram cruciais do ponto de vista da Corte estavam, muitas vezes, entre as maiores preocupações dos setores sociais envolvidos nas dinâmicas políticas locais e provinciais. Ou seja, questões que não estavam entre os maiores dilemas dos poderes centrais - por exemplo, como decidir qual seria a legítima capital da província de Mato Grosso 20 ou como solucionar a divisão da província de Goiás, com a reunificação ou a legitimação do desmembramento do Norte ${ }^{21}$-, para os setores sociais que se faziam representar pela câmara da "Cidade Capital"22 de Mato Grosso ou da "Vila Interina de Natividade" 23, no Norte de Goiás, eram de suma importância. 0 domínio das dinâmicas políticas provinciais, certamente, trará elementos para tornar inteligivel um processo marcado pela diversidade. A produção historiográfica de universidades e institutos históricos, especialmente dos estados de Minas Gerais, Goiás, Tocantins e Mato Grosso, precisa ser consultada para que se supere as lacunas da produção mais conhecida sobre o processo de Independência.

As manifestações das câmaras não são diversas apenas por apresentarem demandas locais, mas também na percepção dos significados da própria adesão e do projeto do futuro a que se referia. A compreensão desta diversidade passa, ainda, pela consciência da crise que caracteriza o periodo. Crise esta que se manifesta na "extraordinária provisoriedade das formas e significados [...], o que se estende tanto à noção de Estado quanto à de nação", sendo que "das diferentes percepções resultam múltiplos projetos políticos"24. Se ao aderirem ao projeto imperial, grupos sociais de diversas 
junto ao Imperador, no momento mesmo da adesão. Sérgio Paulo Moreyra. "O Processo de Independência em Goiás". In Carlos Guilherme Mota (org.). 1822: Dimensões. Tairone Zuliani de Macedo. Império e Região: A dinâmica do processo de Independência e a elite politica em Goiás (1820-1831). Dissertação de Mestrado. Goiânia, UFG: 2004.

\section{2}

A citação é de um documento da Vila de Mato Grosso (antiga Vila Bela) que abrigou uma das Juntas Governativas, rivalizando com Cuiabá o governo da Província. As Câmaras Municipais e a Independência. op. cit. Volume 1. Doc 131. p. 259.

23

Idem. Doc 140. p. 272.

24

István Jancsó \&t João Paulo G. Pimenta. op. cit. pp. 135-136.

25

SOUZA, lara Lis Carvalho. op cit.

26

"Officio da Camara do Rio de Janeiro á Camara da Villa de Taubaté..."

27

As Câmaras Municipais e a Independência. op. cit. Volume 1. Docs 129 a 132. p. 257-261.

28

Arquivo Nacional, Biblioteca Nacional do Rio de Janeiro, Arquivo Histórico Ultramarino (disponivel em $\mathrm{Cd}$-rom graças ao Projeto Resgate), Arquivo Público Mineiro, e Arquivo Histórico Estadual de Goiás e Arquivo Público de Mato Grosso. Somente neste último, os documentos já se encontram digitalizados. regiões celebraram "um novo contrato social que fundava o Brasil como corpo político autônomo"25, esses grupos tinham diferentes percepções tanto da natureza deste pacto, quanto do que seria a nova ordem que se estava construindo e, ainda, de como viriam a se inserir.

Se nos restringirmos às situações em que houve a adesão, temos, em um dos extremos, os vereadores do Senado da Câmara do Rio de Janeiro, para quem a nova ordem era a "Independência, e Liberdade pela Constituição, debaixo de uma Monarquia Constitucional"26, e o pacto implicava a condição de o Imperador jurar respeito à Constituição por fazer; e, no outro, os "fiéis vassalos" da cidade de Mato Grosso que sequer mencionam a Constituição, a Assembléia e o Imperador Constitucional. As palavras Independência e Brasileiros só seriam utilizadas em um documento de 1824. 0 que sua adesão manifesta é a alegria em ver "Sobre o Trono do vasto Império do Brasil ao legítimo herdeiro da Casa de Bragança" e a declaração de "fidelidade Ao Vosso Sangue [...]"27.

Os casos citados constituem os pólos - considerando apenas a documentação já consultada - dentre os quais estão situados diversos outros tipos de manifestações. Uma possivel tipologia das adesões (e da ausência destas) teria como resultado um leque muito mais amplo de percepções da crise política então vivida, do projeto de futuro a que se referiam e da natureza das relações entre os setores sociais que se representam por estas manifestações e o centro político desta nova ordem. A análise documental deverá ser muito mais ampla para que se chegue a esta possivel tipologia ou a explicações conclusivas sobre as adesões. Até o momento somente uma parte dos documentos publicados pelo Arquivo Nacional foi consultada. Além desta e de outras publicações já foram localizadas - mas não examinadas - diversas séries de documentos em algumas instituições 28. A consulta e a análise cuidadosa desse material é o que tornará possivel mapear, classificar e explicar a diversidade presente nas adesões das câmaras municipais. 